\title{
Psychiatrists and Psychologists: Co-operation or Confrontation?*
}

\author{
J. L. T. Birley, Dean, Royal College of Psychiatrists
}

\section{Morning}

On 15 November 1984, as part of the College's Autumn Quarterly Meeting, a whole day conference was held between the Royal College of Psychiatrists and the British Psychological Society, with the overall title 'Psychiatrists and Psychologists: Co-operation or Confrontation?' The meeting, held in the College and in the Lecture Theatre of the Society for Chemical Industry, was gratifyingly oversubscribed.

The first speaker, Dr Frank McPherson, former Chairman of the Professional Affairs Board of the British Psychological Society, presented his paper entitled 'Organization and Professional Problems of Clinical Psychology'. He pointed out that clinical psychology was firstly a very small professionproviding only some 1,300 full-time equivalent posts for the whole of the NHS - and secondly, a young one. There were only fifteen clinical psychologists over the age of forty-five in the whole of Scotland. Over the past twenty years, its role and its method of approach had changed dramatically from assessment to treatment, consultancy and preventive work. At the same time, the work had become more specialized and patients were referred from a wide variety of sources.

Psychologists had become more independent, at least in the administrative sense, although their clinical autonomy remained a matter of some dispute, particularly within the NHS. The administrative and organizational structure of clinical psychology were equally problematic. Promotion was through increased administrative responsibility; there was no educational hierarchy-junior psychologists acquiring tenure on appointment, a very different situation to medical grades. Thus the control which a senior could exercise in terms of, for instance, the type of work undertaken, was, in theory at least, quite limited.

While the numbers of psychologists were increasing, this problem seemed less urgent, but there is now a real possibility of the numbers remaining at the present level, facing psychologists with a bewildering choice of responses to increased demands for their services. Should, for instance, psychologists move to 'more rewarding' patients who responded to their treatments more obviously than, say' the traditional longterm patients in a mental hospital? Dr McPherson felt that psychologists would be called upon to teach treatment techniques to psychiatrists who will be having to manage without a psychologist attached to their services. The question of ultimate 'clinical' as opposed to 'medical' responsibility continued to cause difficulties, as did that of the leadership of

-Report of a Joint Meeting of the Royal College of Psychiatrists and the British Psychological Society. 'multidisciplinary' teams. The fact that Psychology Sections had become separate Units did not necessarily mean that they had much freedom of action. Their budgets were strictly limited, and they were not always on the list of organizations to be consulted in planning procedures.

In contrast to Dr McPherson's account of psychologists wrestling with the awkward facts of independent life, DR James Birley, Dean of the College, concentrated on more theoretical issues, the different approaches of psychiatrists and psychologists. He stated that the College, while valuing the contribution of psychology and insisting that the subject was taught to psychiatrists, did not go so far as to ensure that a psychiatrist would fail the MRCPsych if he or she knew no psychology. There was, he felt, an ambivalent feeling towards psychology and psychologists, and he had certainly found it quite difficult to persuade trainees at the Maudsley to attend psychology lectures. One of the difficulties arose from the differences between 'medical psychology' and 'real or psychologist's psychology'. The former had been largely devised by doctors, and used as an explanation in understanding disease processes. Psychologists, on the other hand, were concerned with functions, present and measured in normal individuals, and then their abnormalities studied in mentally ill people. The difficulty was that the gap between normal and abnormal functions seemed so wide that it was often difficult, if not impossible, to bridge. One contributing factor to this might be that psychologists were more or less obliged to investigate disturbances classified by psychiatrists, and that these may not be the best points of departure. Some of the workers who were happiest in this research were psychologically sophisticated psychiatrists.

Dr Birley stated that the various conceptual gaps had been happily bridged by the psychologists' enthusiastic espousal of treatment. But at a cost: the enthusiasm was directed at how to treat rather than investigating what was being treated. Finally, Dr Birley referred to the eclipse of Wilhelm Wundt, whose view of mental life and psychic causality had been overtaken by positivist and behaviourist thinking. Recently, his views had been re-examined and found to have adumbrated current views of attention and cognition. Dr Birley hoped that psychologists would give more time to investigating these matters in the future, even at the risk of neglecting treatment, as they seemed to be the functions which are so characteristically disturbed in severe mental illness.

The two opening papers were discussed by Professor $\mathbf{M}$. G. GeLDER. He started with issues of confrontation and, in particular, with the issue of responsibility. He noted that these 
issues would arise whether the professionals in question were psychiatrists or psychologists. To some extent responsibility must always be shared. Nevertheless, there must also always remain the final responsibility for a patient's welfare vested in some individual or another. He noted that in an area where psychological problems were associated with medical symptoms and treated with drugs, and where medical disorders could produce psychological symptoms, the person who can deal with all aspects of the case is the doctor. Therefore, unless or until the training of clinical psychologists changes considerably to include the study of medical disorders and pharmacology, the person taking final responsibility must also be a doctor.

Professor Gelder then moved on to the question of training and experience. He said that many doctors found it a little odd that a clinical psychologist of the age of 24 , with normally three years' postgraduate training and two years' clinical work, could assume complete responsibility for his or her work. A doctor of the same age is embarking on six years of increasing responsibility for his work under reducing supervision.

Another area of confrontation was that between community based services and hospital based services, or at least between the philosophies of those operating such services. Professor Gelder noted that this is a source of confusion within as well as between all the professions involved. He thought, however, that matters might be eased if roles could be defined more clearly, bearing in mind both his previous points.

Professor Gelder suggested that the problems of clinical psychologists were especially difficult for two reasons. First, when working in hospital they feel that they are operating under the medical yoke. Secondly, when working in the community they tend to devote more of their time to areas in which knowledge is greatest and less to important areas where ignorance is greater. This leads some psychologists to devote their attentions to the group that Dr Bennett has called the 'worried well'. Professor Gelder asked whether psychologists would be best employed doing that or whether they should devote more time to problems such as chronic schizophrenia and the dementias.

Professor Gelder then turned his attention to areas of co-operation. To some extent service has become associated with treatment, method and style. Professor Gelder contrasted the work of clinical psychologists in the United Kingdom and the United States of America. He said that the practice of psychotherapies by psychologists in the United States is widespread, and indeed a common way of making a living. In the United Kingdom clinical psychologists had turned away from psychotherapy, and a dichotomy had arisen between the clinical psychologists practising behaviour therapy, and psychotherapists who are largely psychiatrists. As a result there is a lack in the United Kingdom of clinical psychologists who have applied scientific approaches to the problems of psychotherapy; in the United States many clinical psychologists have made distinguished contributions of this kind.

When discussing the relationship of basic and applied research, Dr Birley had used the analogy of tunnellers approaching each other from opposite sides of a mountain. This was an evocative image, but Professor Gelder thought that it did not describe very well the way that pure and applied science advanced knowledge in medicine. He gave as an example advances in molecular biology in which the pure scientist had now placed in the hands of the clinicians a powerful tool for research on clinical problems. In the terms of Dr Birley's analogy, the clinician had been given a more effective too--analogous perhaps to the advanced tunnelling machines which work fast and efficiently. In these terms, clinical psychologists can only offer unsophisticated tools-analogous to the picks and shovels of earlier tunnellers. However, to concentrate on this lack of sophisticated research methods is to lose sight of the real contribution that clinical psychologists can make. The value of their research is that they have the special training required to bring scientific methods to bear directly on clinical problems. In this way clinical psychologists have the same important contributions to make to psychiatry that clinical biochemists have made to certain medical problems.

Professor Gelder then contrasted the academic basis of clinical psychology with that of some parts of experimental psychology in which knowledge from neuro-physiology, neuro-anatomy and neuro-pharmacology are being brought to bear on psychological problems. He thought that clinical psychologists have not made the same potentially fruitful links with these other disciplines. Indeed, few clinical psychologists have the background in neuro-physiology and neuropharmacology needed to appreciate the highly relevant advances that are being made in these subjects at present. Professor Gelder added that parallel criticism could be made of the psychiatrists' lack of understanding of modern experimental psychology.

Professor Gelder drew his remarks to a close by commenting approvingly on the progress that he had observed in clinical psychology in recent years. The old 'medical psychology' had done little more than offer what Sir Peter Medawar had termed 'anaesthetic explanations'; explanations which provided a comfortable feeling of understanding what was going on but did little to provide a means of changing the situation, being largely circular in nature. And where clinical psychology did relate to and draw on the scientific basis of academic psychology it could achieve very great scientific strength. Professor Gelder cited the work of Dr John Teasdale, who had investigated the cognitive disorder in depression working in collaboration with the cognitive psychologist, Dr Donald Broadbent. This collaboration had produced work that was of great interest to academic cognitive psychologists as well as to clinicians. As such it exemplified the fruitful links that can be made between basic and applied research in abnormal psychology.

The general discussion that followed might be described as variations on a number of themes and leitmotivs. On the issue of clinical responsibility, psychiatrists maintained that they were already delegating this to a variety of people. There was some doubt as to whether the amended Register of Clinical Psychologists would affect this issue. Of greater concern, to 
both psychiatrists and psychologists, was the matter of autonomy. Both complained that psychologists might change their job description (psychiatrists did likewise, as someone pointed out). Psychologists suspected that their budgets, if not their destiny, were still being covertly controlled by Academic Departments of Psychiatry. Professor Rawnsley protested both innocence and impotence in this matter. A local University-based M.Sc. course in Clinical Psychology was strongly recommended for its effect on the local supply of psychologists. One speaker went further, suggesting that trainees in both disciplines should attend a common training programme. This was said to be a more popular notion with trainees than trainers and certainly the suggestion was not taken up by any other speaker. Fortunately, one psychiatrist had the courage to express forceful views on the demands for autonomy by psychologists. He anticipated a multidisciplinary Declaration of Independence, if not a war, and called on his colleagues to hold the line. He received no support. Indeed, even before lunch there were signs of at least peace if not an alliance. The call to unity was strengthened in the summing up. Dr McPherson suggested that the College and the BPS should draw up joint guidelines on the 'norms' for a District Psychology Service. Dr Birley warned the audience of the arrival on the scene of hard-nosed managers trained in business, and familiar with the writings of Professor Archie Cochrane. They would be asking both professions awkward questions about their efficiency and effectiveness.

\section{Afternoon}

In the afternoon the participants split into four working groups, representing different aspects of psychiatry, who then reported their deliberations.

Summarizing for the mental handicap group, DR KEN DAY reported that there had been more common ground than disagreement in their discussions. It was agreed that the mental handicap 'scene' was different, in a transitional period in which psychiatrists were aiming to provide care only for the sizeable minority of the mentally handicapped who were psychiatrically disordered. Psychologists were seen as facilitators of programmes for change with special skills both in assessment and devising treatment programmes. Both professions had been having problems in recruitment into the field of mental handicap and felt that more postgraduate training in this subject was required. On the issue of 'clinical responsibility', they felt that this needed to be looked at in three ways: from the 'professional', 'legal' and 'ethical', as the implications and obligations were different.

Summarizing for the 'old age' group, Dr Geoffrey GARLAND reported that a need for shared skills was generally felt, but that at present there were only twenty-four psychologists in the United Kingdom who were working whole-time in the old age field. Particular problems which were identified were the hierarchical staff structures and the lack of shared training between psychologists and psychiatrists. As contributions to treatment, at present the most effective seemed to be 'total push-from false teeth to antidepressants, and the effective ingredients had not been successfully identified. Professor Arie had stated that because of the very few psychologists working in the old age field, their contribution both to treatment and research could not be adequately assessed. It was suggested that psychologists know more about both normal development and normal ageing than did psychiatrists. The general consensus was that there was a shortage of resources, of medical support and of training opportunities in old age care.

Speaking for the child and adolescent group, DR WoLKIND and MR CoRNwall managed to produce some real problems, particularly about the present and future role and management of Child Guidance Clinics. Should there be a 'rotating chairman' rather than a single director? Are Child Guidance Clinics getting out of date compared to other services for children? In general, the scene seemed more co-operative than confrontatory, but the need for more joint training was emphasized and also for some more intense meetings to look at some of the main problems.

The discussion in general adult psychiatry, reported by $D_{R}$ PETER ROHDE, had focused on the functions, advantages and disadvantages of the multidisciplinary team. In general, there seemed to be few problems where people got on well together and/or respected each other, but even the most 'multidisciplinary' psychiatrists clearly had a feeling that he or she had a right to put a foot down and insist that something be done or not done. Exactly over what issue was never clarified, and perhaps it was a sort of professional nuclear deterrent, a phallic symbol lurking somewhere and presented on ceremonial occasions, but never actually fired in anger. The ideal of a totally united team was not perhaps a good one. The group took some comfort from another saying of Dr Douglas Bennett's: 'God help the patient whom the staff agree about'. The best team, like a large family, had a space of variety in the individual approaches which the patient can appreciate, benefit from, and occasionally exploit.

In the discussion, there was a general feeling that perhaps some of the real problems between the professions were not being tackled, but nobody was quite sure what they were. It was also felt that the professions needed to unite in joint planning to make their case to the tough-minded allocators and organizers. 'Creatures squabbling in a rock pool unaware of the rising tide' was a vivid analysis provided by one speaker. But, to survive, they should take advantage of the rising tide, and it was generally agreed that the meeting had been a great success and another one, more focused and more hard-hitting, should be planned in the near future.

\section{Baron C. ver Heyden de Lancey Prize}

The Baron C. ver Heyden de Lancey Prize in Medico-Legal Studies for 1984 has been awarded to Dr Malcolm Weller,
Friern Hospital, London N11, for his essay 'The MedicoLegal Issues of Compensation Following Head Injury'. 